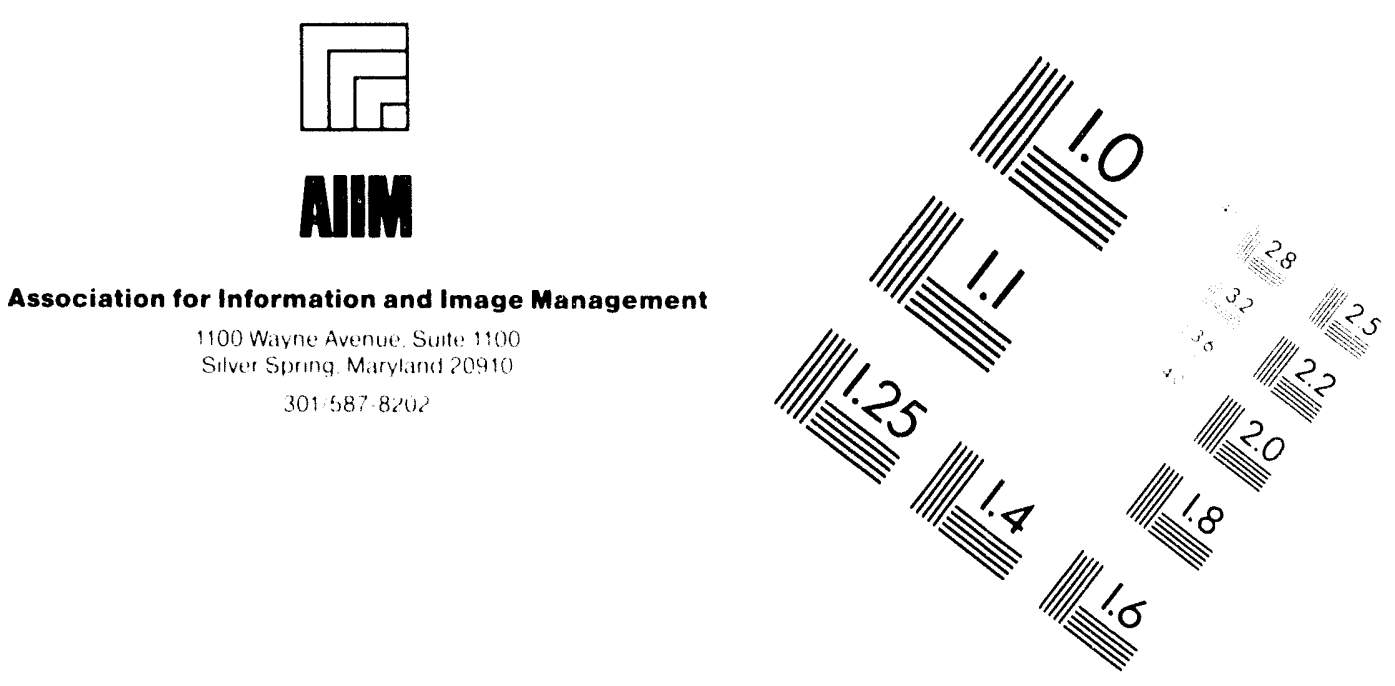

\title{
Centimeter
}

$\begin{array}{llllllllllllllll}1 & 2 & 3 & 4 & 5 & 6 & 7 & 8 & 9 & 10 & 11 & 12 & 13 & 14 & 15 & 15\end{array}$

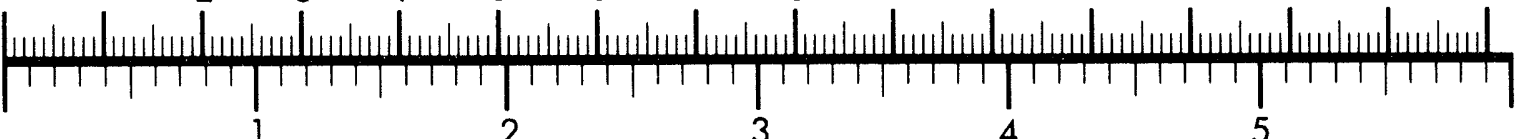
Inches
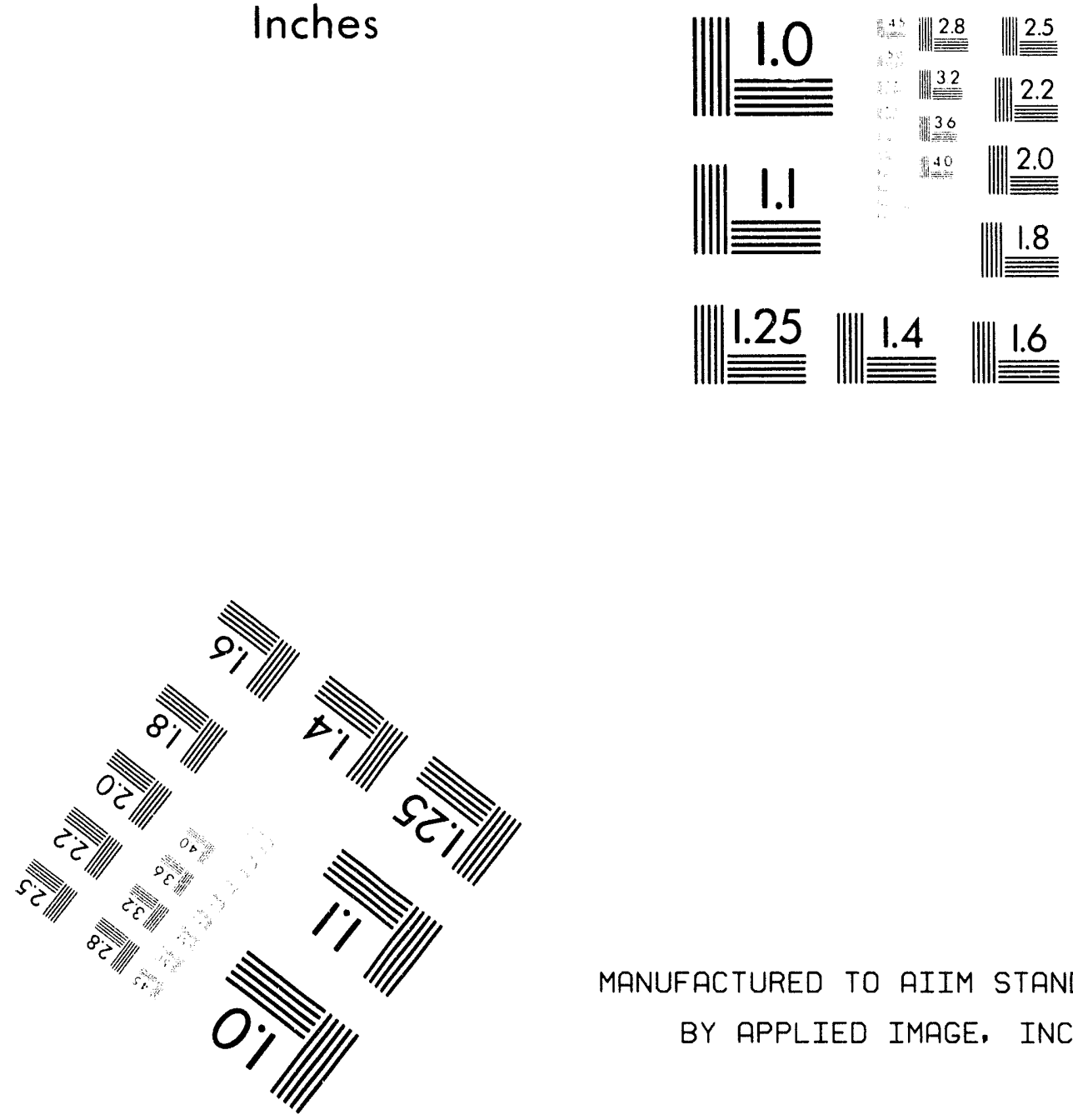

MANUFACTURED TO AIIM STANDARDS

BY APPLIED IMAGE, INC.

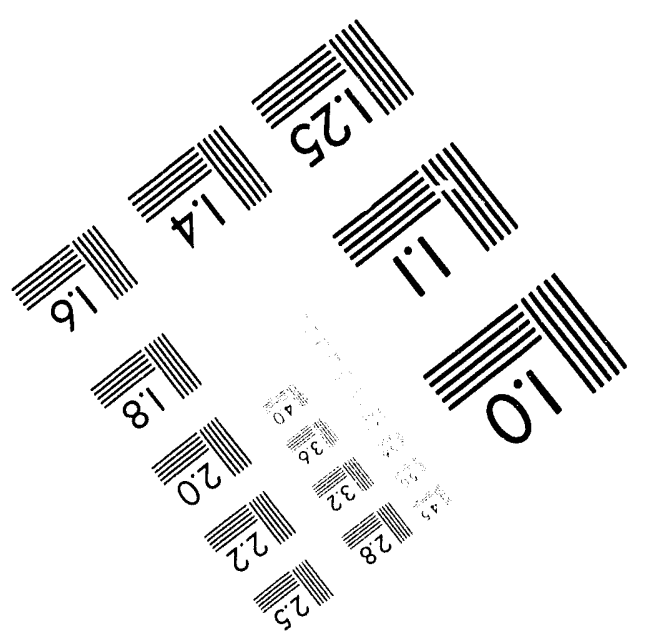



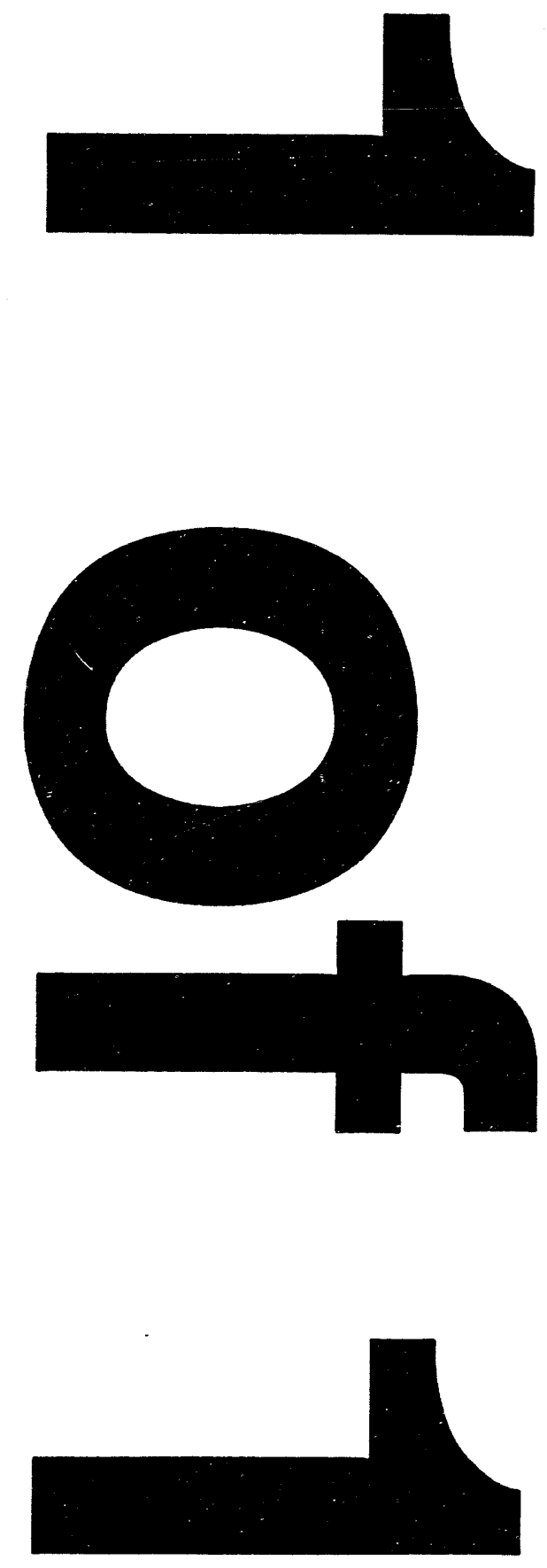

, 


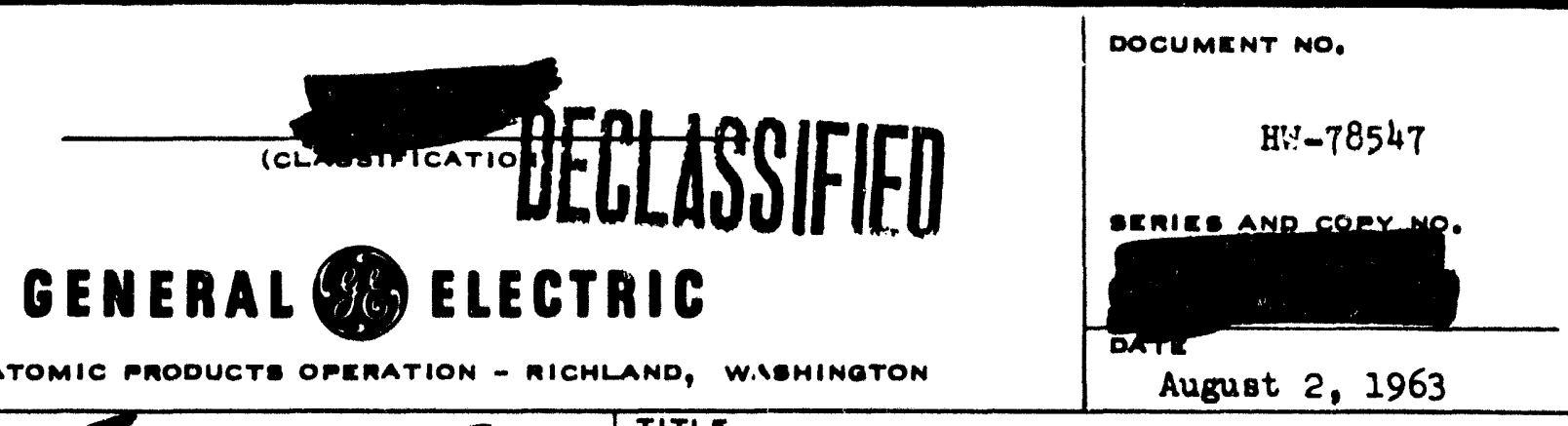

MANFOND ATOMIC MRODUCTE OPERATION - RICHLAND, WISHINGTON

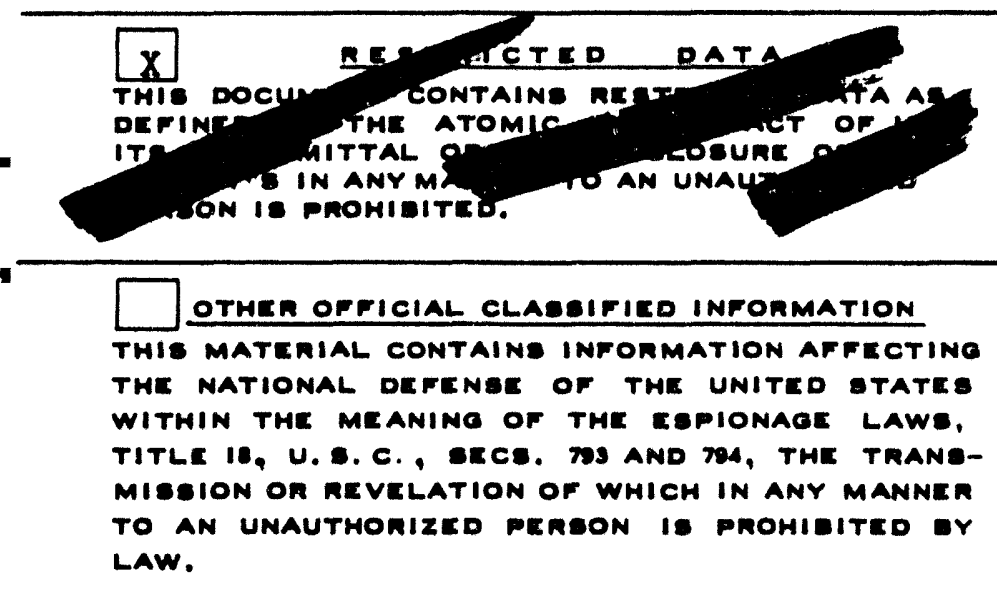

THIS DOCUMENT WOT DE LEFT UNATTENDEM

THIS DOCUMENT WOT DE LEFT UNATTENDP
TO IT. WHP TO IT. WH' - WhILE it is roun? GuAnp of Files, it is roir

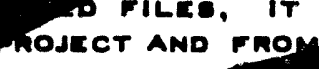
MOJECT AND FROM MORIzED PERSON.
RESIDENCE Is TITLE

TO SION IN THE GPACE PROVIDED MELOW.

\section{COMPARISON OF PHYSICS PARAMETERS FOR N AND $K$ REACTORS}

\section{AUTHON}

Paul F。 Nichols

R。 N1180n

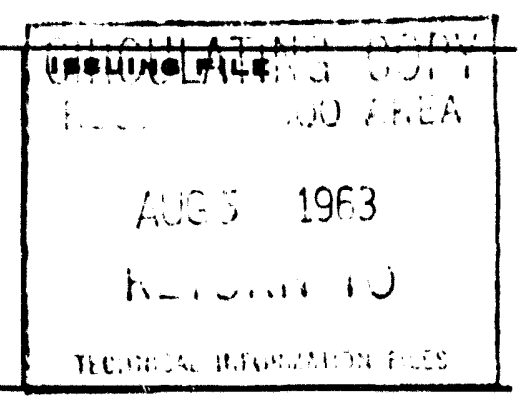

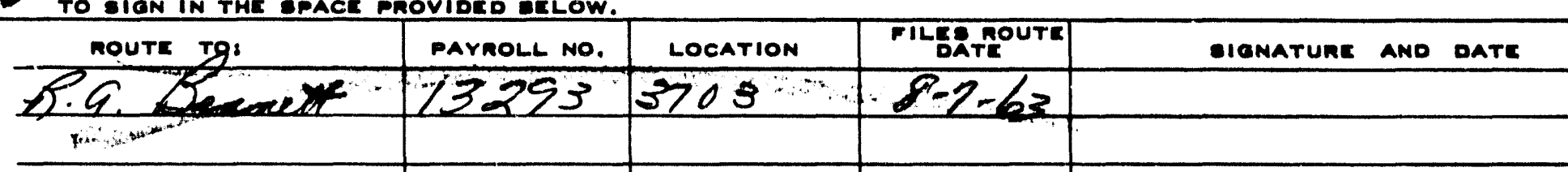

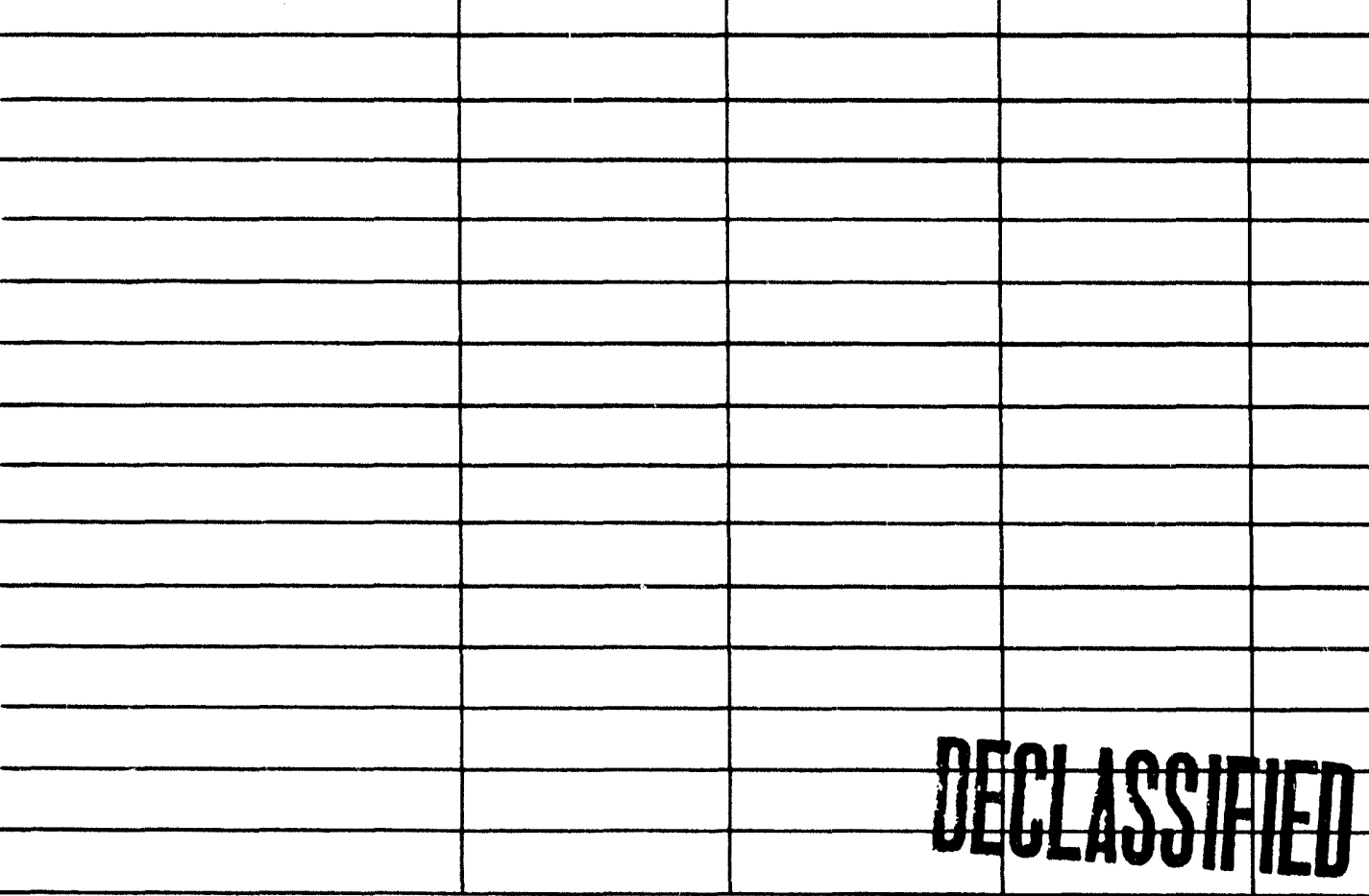

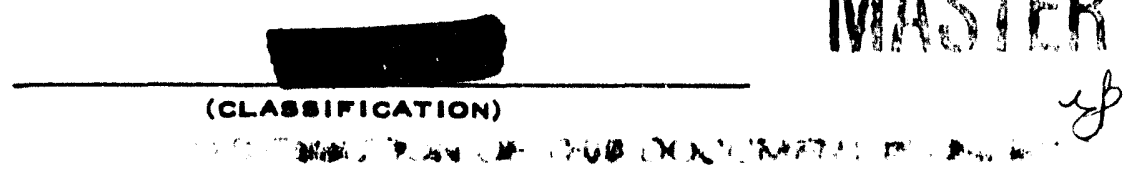


August 2, 1963

Paul Fo Nichols

Reactor Physics

Research and Engineering

N-REACTOR DEPAIRTMENT

R. Nilson

Reactor Physics

Research and Engineering

IRRADIATION PROCESSING DEPARTMENT

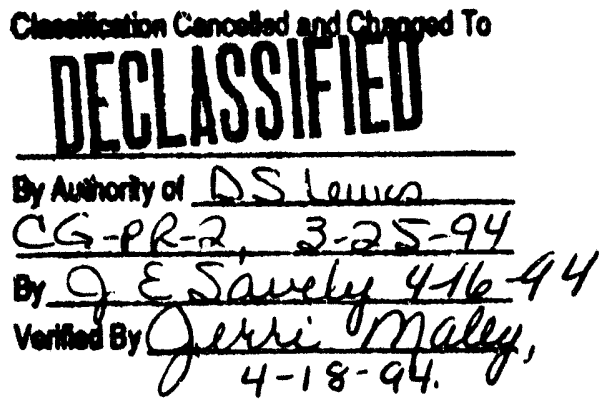

\section{DISTRIBUTION}

1. T. W. Ambrose

2. R. A. Bennett

3. W. A. Blyckert

4. W. J. Dowls

5. O. H. Greagor

6. R. 0. Gumprecht

7. J. P. Hamric

8. L. E. Kusler

9. L. W. Lans

10. M. C. Leverett

11. R. H. Meichle
12. E. E. Mills

13. P. F. Nichols

14. R. Nilson

15. G. F. Owsley

16. R. V. Poe

17. R. J. Shields

18. H. Toffer

19. W. K. Woods

20.-21. Extras

22. 300 Area File

23. Record Center

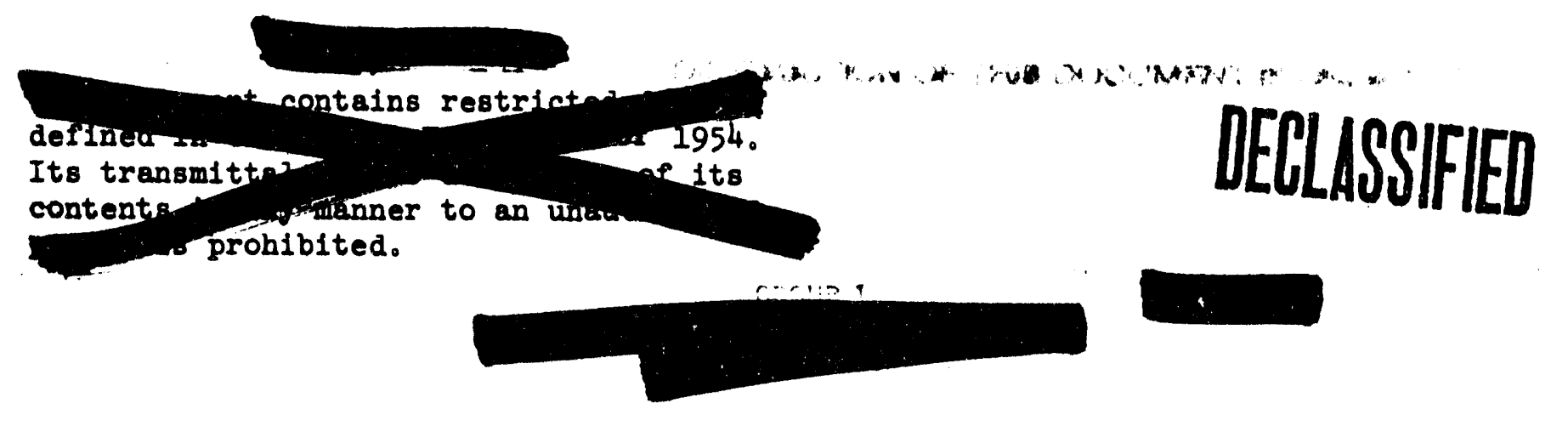




\section{COMPARISON OF PHYSICS PARAMETERS FOR $N$ AND K REACTGRS}

1. Power, Conversion Ratiog, Westcott Flux, Neutron Temperature and "r" Value The following physics parameters bave been selected by the authors as representing the best set presently avallable for comparison purposes. Although these numbers may differ from some quoted earlier in hazards reports, etc., they represent the most consistent set we have for the present purpose.

The parameters are summarized in Table I.

TABLE I PHYSICS PARAMETERS

\begin{tabular}{|c|c|c|}
\hline & IN & $\mathbf{K}$ \\
\hline Reactor Power & 4000 & 4400 \\
\hline $\begin{array}{l}\text { Average Westcott Core Flux } \\
\text { (Fiel) }\end{array}$ & $2.67 \times 10^{13}$ & $2.93 \times 10^{13}$ \\
\hline $\mathbf{T}_{\mathbf{n}}$ & $700^{\circ} \mathrm{K}$ & $650^{\circ} \mathrm{K}$ \\
\hline $\mathbf{r}$ & 0.105 & 0.0625 \\
\hline $\begin{array}{l}\text { Conversion Ratio for } 6 \% \text { Pu } \\
\text { Production Only in } 8 \mathrm{~m} / \mathrm{MWD}\end{array}$ & $\begin{array}{l}.865(21.6 \mathrm{lb} / \mathrm{ft} \text { fuel }) \\
.885(24.0 \mathrm{lb} / \mathrm{ft} \text { fuel })\end{array}$ & $.885 \mathrm{KV}$ fuel \\
\hline
\end{tabular}

The bases for these numbers are as follows:

a. Power Level

This is the design level for $N$ and the present administrative limit for $\mathrm{K}$.

b. Average Westcott Core Flux in Fuel

This is an over-all average for $N$ and an average for $K$ in the natural uranium core region. 
c. Neutron Temperature

These numbers are for fuel regions estimated from MOFDA calculat.lons and both have arbitrarily been reduced $50^{\circ} \mathrm{K}$ to be in line with IPD operating experience with temperature and exposure transients. d. "r" Value

These are average values in the fuel. The numbers were obtained by averaging FLEX and MOFDA calculations.

e. Conversion Ratio

The value for $\mathrm{N}$ Reactor at $6 \% \mathrm{Pu}^{240}$ is fro FLEX calculations for $21.6 \mathrm{lb} / \mathrm{ft}$ and $24 \mathrm{lb} / \mathrm{ft}$ fuel with the staplard normalizations used In HW-77806, "Phys1cs Input Data for Economics Studies; Tube-1n-Tube Fuel Elements" - P. F. Nichols (Secret), 1.e., $8.6 \% \mathrm{Pu}^{240}$ at $1300 \mathrm{MWD} / \mathrm{T}$ and a conversion ratio of 0.82 e $1200 \mathrm{MWD} / \mathrm{T}$ for the $21.6 \mathrm{lb} / \mathrm{ft}$ fuel element. The value for $\mathrm{K}$ Reactor at $6 \% \mathrm{Pu}^{240}$ is from HW-50300 B-Rev., "Plutonium Conversion Tables" - A. D. Vaughn (Secret) and assumes that $12 \%$ of the MWD is in KV enriched fuel and $88 \%$ of the MWD in KV natural fuel.

\section{Reactor Rates}

Ratios of reaction rates in $N$ Reactor and $\mathrm{K}$ Reactor have been calculated from the flux, $r$, and $T_{n}$ values shown in Table I for several target materials. These ratios are listed in the "Average Core Flux" row in Table I。

Because the average to peak flux ratios are different in $N$ Reactor and $\mathrm{K}$ Reactor $(\sim 0.63$ in $N$ and $\sim 0.56$ in $K)$, rat10s of reaction rates are also 11sted in the "Peak Core Flux" row in Table II. 


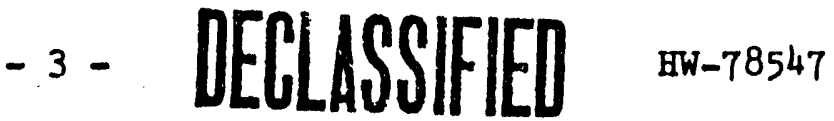

The ratios shown in Table II are valid only for dilute absorbers in the flux and spectral environments of production fuel in the two reactors.

TABLE II

RATIO OF REACIION RATES (N TO K) PER TARGET ATOM

A. Productive Capture Reactions

Target Atom $\mathrm{I} / \mathrm{v} \mathrm{Np}^{237} \mathrm{Am}^{241} \mathrm{Am}^{243} \mathrm{Pu}^{240} \mathrm{Pu}^{242} \mathrm{Tu}^{232} \mathrm{Pu}^{241} \mathrm{U}^{236} \mathrm{Pu}^{239} \mathrm{U}^{235}$ Average Core

$\begin{array}{llllllllllll}\text { Flux } & 0.91 & 1.10 & 1.07 & 1.24 & 1.41 & 1.43 & 1.28 & 0.94 & 1.73 & 1.00 & 0.94\end{array}$

Peak Core

Flux

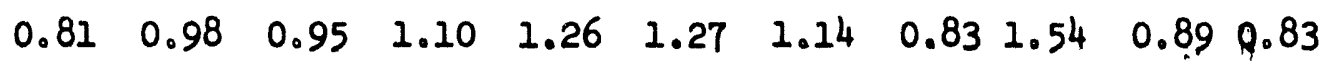

\section{B. Destructive Fission or Capture Reactions}

Target Atom $1 / v$ (Cepture) $\mathrm{Pu}^{239}$ (Fission) $\mathrm{U}^{235}$ (Fission) $\mathrm{Pu}^{241}$ (Fission)

Average Core

$\begin{array}{lllll}\text { Flux } & 0.91 & 0.98 & 0.91 & 0.94\end{array}$

Peak Core

$\begin{array}{lllll}\text { Flux } & 0.81 & 0.87 & 0.81 & 0.83\end{array}$

Productive $1 / v$ capture reaction targets would include $L 1^{6}$ and $B i$, and destructive $1 / v$ reaction targets would include $A^{242}$ (fission), $\mathrm{Cm}^{243}$ (fission), $\mathrm{cm}^{244}$ (capture), and $\mathrm{cm}^{242}$ (capture) which is destructive in the production of $\mathrm{Cm}^{242}$ but not $\mathrm{Cm}^{244}$. 

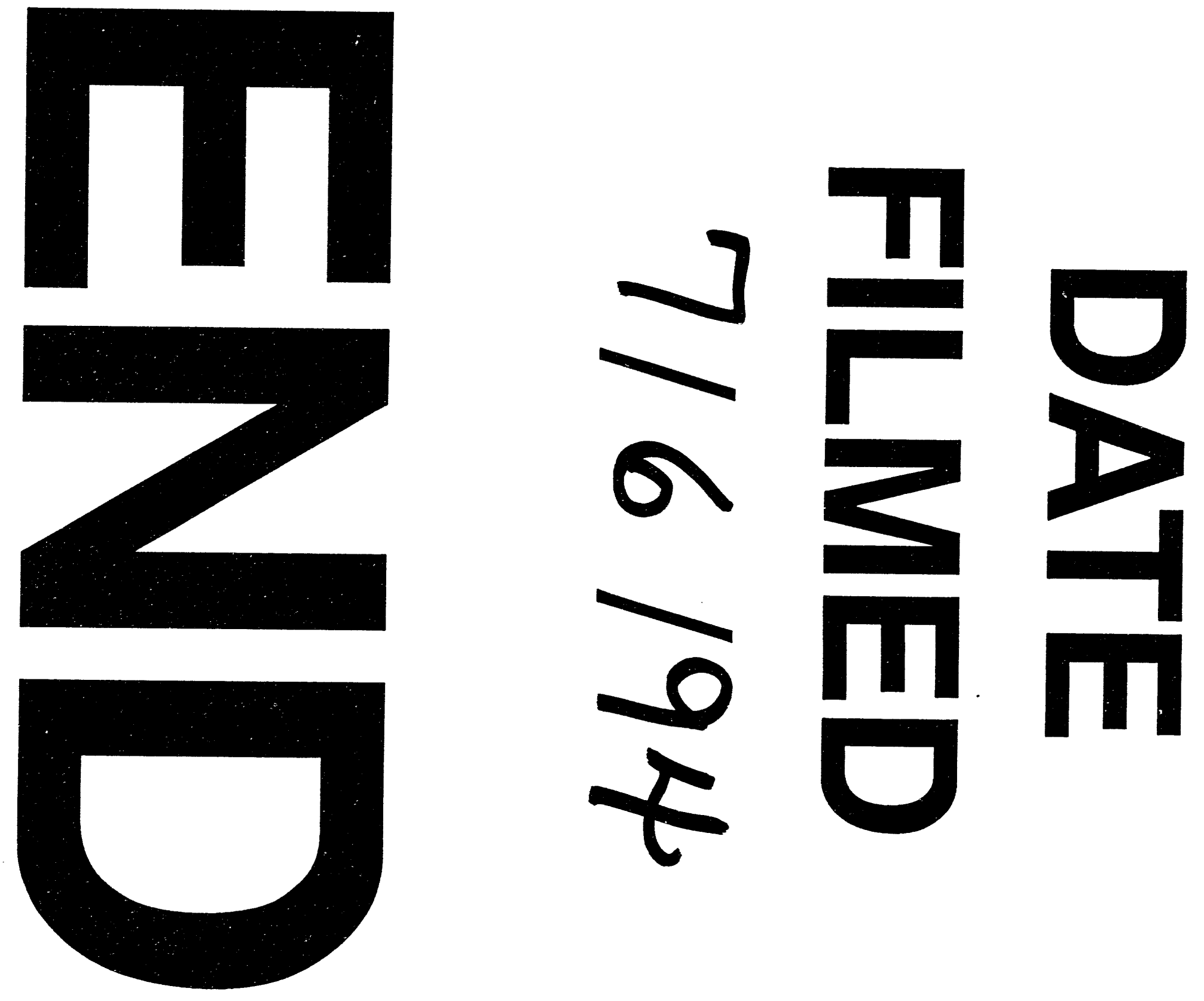
